\title{
GUSTAVO CAPANEMA E O ENSINO SECUNDÁRIO NO BRASIL: A INVENÇÃO DE UM LEGADO
}

Sérgio de Sousa Montalvão*

\section{RESUMO}

Este artigo coloca um problema para a história política da educação: qual seria o indicativo da opção em fazer do ensino secundário o ramo mais atrativo do ensino médio, em um tempo de mudança acelerada para um protótipo de uma sociedade de massas, organizada em torno de um incipiente mercado de trabalho livre, alavancado pelo crescimento da produção industrial e do modo de vida urbano? Apesar dos resultados controversos dessa opção, incapaz de romper com o modelo educacional elitista, um trabalho de construção social da memória fez com que a reforma organizada pelo ministro Gustavo Capanema em 1942 fosse reconhecida como sinônimo da educação de qualidade. Neste sentido, entender as relações do Estado modernizador com os setores mais conservadores da sociedade, fortemente representados pelas instituições educacionais privadas, reprodutoras dos processos escolares de seletividade social, pode ser um caminho frutífero de pesquisa.

Palavras-chave: Gustavo Capanema, ensino secundário, modernização, memória.

\footnotetext{
*Universidade Federal Fluminense (UFF), Niterói/RJ, Brasil.
} 


\title{
GUSTAVO CAPANEMA Y LA EDUCACIÓN SECUNDARIA EN BRASIL: LA INVENCIÓN DE UN LEGADO.
}

\section{RESUMEN}

Este artículo plantea un problema para la historia política de la educación: cuál sería el indicio de la opción de hacer de la educación secundaria la rama más atractiva del bachillerato, en una época de cambio acelerado hacia un prototipo de sociedad de masas, organizada en torno a un incipiente mercado laboral libre, apalancado por el crecimiento de la producción industrial y el estilo de vida urbano? A pesar de los polémicos resultados de esta opción, incapaz de romper con el modelo educativo elitista, una obra de construcción social de la memoria hizo que la reforma organizada por el ministro Gustavo Capanema en 1942 fuera reconocida como sinónimo de educación de calidad. En este sentido, comprenderlas relaciones del Estado modernizador con los sectores más conservadores de la sociedad, fuertemente representados por las instituciones educativas privadas, reproduciendo procesos escolares de selectividad social, puede ser un fructífero camino de investigación.

Palabras clave: Gustavo Capanema, educación secundaria, modernización, memoria.

\section{GUSTAVO CAPANEMA AND SECUNDARY EDUCATION IN BRAZIL: THE INVENTION OF A LEGACY}

\begin{abstract}
This article poses a problem for the political history of education: what would be the indication of the option of making secondary education the most attractive branch of secondary education, in a time of accelerated change to a prototype of a mass society, organized around an incipient free labor market, leveraged by the growth of industrial production and the urban way of life? Despite the controversial results of this option, unable to break with the elitist educational model, a work of social construction of memory made there for organized by Minister Gustavo Capanema in 1942 to be recognized as a synonym for quality education. In this sense, understanding the role of the relations of the modernizing state with the more conservative sectors of society, strongly represented by private educational institutions, reproducing school processes of social selectivity, can be a fruitful path of research.
\end{abstract}

Keywords: Gustavo Capanema, secundarye ducation, modernization, memory.

\section{GUSTAVO CAPANEMA ET L'ENSEIGNEMENT SECONDAIRE AU BRÉSIL: L'INVENTION D'UN HÉRITAGE}

\section{RESUME}

Cet article pose un problème pour l'histoire politique de l'éducation: quelle seraitl'indictif de l'option de faire de l'enseignement secondaire la branche plus attractive du lycée, à une époque de changement accéléré vers un prototype de société de masse, organisé autour un marché du 
travail libre naissant, mis à profit par lacroissance de la production industrielle et du mode de vie urbain? Malgré les résultats controversés de cette option, incapable de rompre avec le modèle éducatif élitiste, untravail de construction sociale de la mémoire a fait que la réforme organisée par le ministre Gustavo Capanema en 1942 soitre comme synonyme d'une éducation de qualité. En ce sens, comprendre les relations de l'État modernisateur avec les secteurs les plus conservateurs de la société, fortement représentés par les établissements d'enseignement privés, reproducteurs des processus scolaires de sélectivité sociale, peut être une voie de recherche fructueuse.

Mots-clés: Gustavo Capanema, enseignement secondaire, modernisation, mémoire. 


\section{INTRODUÇÃO'}

Novembro de 1942. Completavam-se cinco anos do Estado Novo. O número 21 da revista Cultura Política, publicada no Rio de Janeiro pelo Departamento de Imprensa e Propaganda (DIP), trazia uma "reportagem especial" sobre a "administração pública no Estado Nacional". Reuniram-se nela informações sobre todos os ministérios e departamentos que formavam o governo de Getúlio Vargas. ${ }^{2}$ A coesão lógica dessa escrita comemorativa, a seleção das medidas ressaltadas, mantendo-se apenas a continuidade e o consenso entre elas, expõe a produção de uma memória institucional. Para tentar compreendê-la, como parte da cultura nacional-estatista do período (REIS FILHO, 2015), iremos nos ater ao conceito do "trabalho de enquadramento da memória" (POLLAK, 1992).

A memória enquadrada resulta de uma operação política em nome de uma interpretação do passado, que "procura definir e reforçar sentimentos de pertencimento e fronteiras sociais entre coletividades de tamanhos diferentes: partidos, sindicatos, igrejas, aldeias, regiões, clãs, famílias, nações etc" (POLLAK, 1992, p. 10). O Brasil do Estado Novo passou por uma experiência desse tipo, quando suprimiu o pacto federativo, retirando em definitivo o poder dos governadores para reforçar um programa autocrático de reconstrução nacional. Educação, saúde e trabalho estiveram na linha de frente desse programa, resumindo os esforços da nova elite dirigente, cujo núcleo central dizia-se representativo da "revolução de 1930", no sentido de dar continuidade ao "saneamento moral e físico" da população.

É nesse contexto que a organização do ensino pós-primário pelo governo central se torna uma prioridade, desde a abertura do Ministério dos Negócios

\footnotetext{
${ }^{1}$ Agradeço a leitura e as observações críticas das professoras Cláudia Calmon e Elaine Bortonne, assim como aos pareceristas anônimos desta revista. Os erros e as limitações do texto são de minha inteira responsabilidade.

${ }^{2}$ O Ministério da Educação e Saúde no quinquênio 1937-1942. Cultura Política (Revista Mensal de Estudos Brasileiros), n. 21 (Edição comemorativa do $5^{\circ}$ aniversário do Estado Nacional). Rio de Janeiro, Departamento de Imprensa e Propaganda (DIP), novembro de 1942, p. 21.
} 
Interiores da Educação e Saúde Pública (MESP), secretaria de Estado criada em decorrência do Decreto $\mathrm{n}^{0}$ 19.402, de 14 de novembro de 1930, ainda nos primeiros dias após o golpe que afastou Washington Luís da presidência da República. No parecer da memória oficial, porém, a sua estruturação definitiva só iria ocorrer em função da Lei $n^{0}$ 378, de 13 de janeiro de 1937. 3 Nesta última data, a condução do ministério estava nas mãos de Gustavo Capanema, político mineiro que permaneceria no cargo de ministro da Educação de 1934 a 1945.

A ascensão de Capanema esteve amparada na larga influência das organizações católicas sobre a sociedade política após a "revolução de 1930", promovida pela vontade de clérigos e leigos em acionar um projeto de restauração do poder da Igreja no mundo moderno. $\mathrm{O}$ agir do Estado sobre a questão social em muito estava concentrado neste aparato administrativo que, deve-se lembrar, não tomava decisões apenas sobre a educação, mas também sobre a saúde, a cultura e a assistência social. Sendo assim, continuamente, o ministério dirigido por Gustavo Capanema tornou-se alvo das correntes de opinião e interesses, mais conservadoras ou progressistas, existentes na sociedade brasileira. No período ditatorial do Estado Novo, entretanto, após um complexo jogo de posições, sobressaíram as orientações emanadas da Igreja Católica e do Exército (SCHWARTZMAN, BOMENY E COSTA, 1984; HORTA, 1994).

Mais do que qualquer outra, a figura de Capanema se entrelaçaria com a do ministério dirigido por ele neste longo período de onze anos, cabendo-lhe conduzir as inciativas do Inquérito sobre a Educação Nacional (1936), o Plano Nacional de Educação (1937) e a Lei Orgânica do Ensino Secundário (1942). Esta última foi apresentada como o corolário da modernização desse segmento do ensino, iniciada com a reforma de Francisco Campos (1931-1932), que encerrou definitivamente a era dos exames parcelados 4 e universalizou o sistema seriado

\footnotetext{
3 Com esta lei, aprovada no período constitucional de 1934-1937, o ministério comandado por Gustavo Capanema recebeu uma nova organização administrativa e passou a se chamar Ministério da Educação e Saúde (MES). Daí em diante, a sua atuação seria estendida mais efetivamente no campo da cultura, pela criação do Serviço do Patrimônio Histórico e Artístico Nacional (SPHAN).

4 Em que era possível solicitar a aplicação individualizada do exame de aprovação em uma
} 
de frequência obrigatória em dois ciclos: fundamental (de cinco anos) e complementar (de dois anos).

Considerado estratégico pelo potencial de formação do caráter cívico dos seus estudantes, o ensino secundário das reformas Campos e Capanema consolidou um sistema educacional dualista, em que estes se tornavam os únicos a adquirirem permissão para se candidatarem, sem nenhuma restrição, aos exames de acesso ao ensino superior. Assim era possível ascender, pelos estudos, à elite idealizada na Era Vargas: católica, masculina, de formação clássica e disciplina militar (BOMENY, 1994, p.137). A quebra integral desse sistema exclusivista de barreiras e interdições, guardado no imaginário coletivo como a era de ouro da educação de qualidade, em que prevaleceram o rigor e a disciplina, não obstante os elevados índices de reprovação e abandono escolar, ocorreria somente após a aprovação da Lei de Diretrizes e Bases da Educação (LDB), sancionada pelo presidente João Goulart, em 20 de dezembro de 1961 (NUNES, 2000).

O problema de pesquisa a ser trabalhado neste artigo refere-se à maneira pela qual a elite dirigente, em especial a responsável pelo aparato administrativo do Ministério da Educação, investiu em uma política direcionada a privilegiar o ensino secundário. Em um tempo de mudança acelerada de uma sociedade predominante rural, e até pouco tempo escravista, para um protótipo de uma sociedade de massas, organizada em torno de um incipiente mercado de trabalho livre, alavancado pelo crescimento da produção industrial e do modo de vida urbano, qual seria o indicativo político desta opção de popularizar esse ramo do ensino médio em detrimento dos demais, tornando-o o legado de uma época?

A resposta que procuramos dar a essa indagação nos leva a refletir sobre as alianças formadas para gerir as decisões do Estado modernizador em um período de autoritarismo latente e manifesto. Considerando a partir de

determinada disciplina, sem a necessária participação nas aulas em ambiente escolar, isentando-se desta, no caso de aprovação, para fins de conclusão do curso e opcional ingresso em uma faculdade. 
Mannheim (1974 [1933]) que a democracia se caracteriza pelo modo de seleção das elites, a manutenção do ensino secundário como elemento seletivo central, em seu papel de ordenar as competências a serem alcançadas no processo de escolarização, nos traz algumas pistas a serem desenvolvidas neste texto. A mais pulsante pode ser observada na disputa curricular que culminou com a reforma Capanema.

Nossa pesquisa procura mostrar que essa política educacional lançou mão de objetivos decorrentes da acomodação de interesses privados, projetados como de interesse nacional após a mediação do Estado5. Na exposição de motivos da Lei 4.244, de 9 de abril de 1942, encontramos a preocupação em fazer do ensino secundário um instrumento para fortalecer a "consciência patriótica", a fim de preparar seus estudantes para chegarem à condição de "individualidades condutoras", capazes de se sobressaírem às massas, assumindo "responsabilidades maiores dentro da sociedade e da nação". 6 Essa era uma aposta elitista no futuro do país, pela qual os sentimentos nacionalistas foram arregimentados para frear as tendências de democratização da cultura. 7 Desse modo, o processo de escolarização esteve orientado a selecionar os mais aptos dentro dos seus padrões formativos, admitindo ter um grupo de excelência, distanciado dos demais, recebendo um preparo específico com base no

\footnotetext{
5 O empresariado de serviços educacionais mantém uma presença ativa na história política do Brasil contemporâneo, estabelecendo coalisões de interesse junto a partidos e associações de classe. Inicialmente detentora de uma fisionomia predominantemente confessional católica, essa fração empresarial adquire novas feições sobretudo após o golpe de 1964. No tempo presente, a sua atuação tem sido influenciada pela criação de novos tipos de negócios e também pela mediação política sob a forma de think tanks e organizações da sociedade civil de interesse público. Essas mudanças, entretanto, não cessaram a dinâmica de buscar no Estado uma fonte de financiamento em nome dos interesses gerais da sociedade.

6 BRASIL. Exposição de motivos do Decreto-lei 4.244 de 9 de abril de 1942.

7 Retomamos mais uma vez aqui a referência a Mannheim (1974 [1933]), em sua discussão sobre o "desenvolvimento crescente dos padrões democráticos de pensamento e conduta" (p. 141), usando-a como um contraponto à Era Vargas. Em nossa leitura, o Estado modernizador obstruiu as saídas democratizantes para os impasses da construção nacional. No campo educacional, especificamente, percebe-se uma estigmatização da pedagogia moderna, com o abandono das propostas renovadoras em nome de um estilo ornamental e acumulativo do ato de ensinar. A identificação da qualidade escolar pela aquisição de uma formação geral, disseminada junto à expansão das redes de ensino, aponta para o predomínio da cultura de alta classe média, incapaz de "proporcionar um ideal existencial para as grandes massas" (Mannheim, 1974 [1933], p. 195).
} 
humanismo clássico e no cientificismo enciclopédico (ou seja, em tradições intelectuais coincidentes com a civilização ocidental, na qual se imaginava estar fundado o Brasil).

\section{UMA PERTINENTE INQUIETAÇÃO}

O Ministério da Educação teve um lugar de destaque na edição de Cultura Política relativa ao quinquênio do Estado Novo. O seu histórico políticoadministrativo foi o primeiro a ser sumariado, considerando o "proeminente lugar" por ele ocupado na "cronologia da revolução brasileira". 8 Entre o que foi selecionado na reportagem, destacam-se: 1) a montagem do aparato administrativo do ministério e 2) a organização do ensino secundário. Atendendo às necessidades deste artigo, iremos nos restringir apenas ao último item.

A matéria dividiu a história do ensino secundário no Brasil pós-1930 em duas fases. A primeira delas, iniciada com a reforma Francisco Campos (primeiro titular do MESP, de 1930-1932), teria se caracterizado "pela expansão e desenvolvimento do sistema escolar", enquanto a segunda, durante a gestão de Gustavo Capanema (1934-até aquele momento), estaria sendo marcada por esforços "no sentido de melhorar e elevar o nível do curso". 9 Assim, a recém apresentada Lei Orgânica do Ensino Secundário (Lei 4.244, de 9 de abril de 1942), seria a culminância deste último período. Expansão e qualificação teriam se sucedido, de modo a criar um todo orgânico que, no conjunto, daria origem a um legado.

A razão do contínuo interesse no aperfeiçoamento deste nível de ensino foi assim colocada em uma palestra da responsável pela Divisão de Ensino Secundário do Ministério da Educação, sra. Lúcia Magalhães:

\footnotetext{
8 O Ministério da Educação e Saúde no quinquênio 1937-1942, p. 23.

9 Idem, p. 24.
} 
A reforma Campos é a mais sábia e mais perfeita legislação porque tem passado o ensino no Brasil.

Dirão agora talvez os que me ouvem: mas se o sistema atual é tão bom, por que mudar? Saliento mais uma vez que a tendência é para reformar alguns pontos sem atentar contra a estrutura do sistema. Depois, é certo, como se vê da resenha publicada pelo Bureau International d' Education de Géneve 1937 ( $\mathrm{n}^{\circ}$ 56), que o ensino secundário é uma "pertinente inquietação", o que Fernando Azevedo atribui ao fato de ser este grau de ensino o que tem mais violentamente sofrido o contra choque das transformações sociais, econômicas e políticas dos últimos tempos.

É esta pertinente inquietação, que em quase todos os países se vem traduzindo por constantes reformas, tanto em extensão como em intensidade. ${ }^{10}$

A "pertinente inquietação" que rondava o ensino secundário era provocada pela indagação sobre o que fazer com a educação continuada dos adolescentes, em um mundo de intensas "transformações, sociais, econômicas e políticas". Um primeiro passo foi dado quando a revolução francesa introduziu a noção de educação progressiva, estabelecida pela sequência dos níveis primário e secundário. Este último nível foi disseminado inicialmente nas escolas centrais do período termidoriano, depois substituídas pelos liceus da reforma napoleônica de 1802. Enquanto as escolas centrais ofereciam uma educação de caráter enciclopédico em regime de externato, com unidades abertas em todos os departamentos territoriais, os liceus, em número mais restrito, se voltaram para a educação literária de uma elite administrativa de dirigentes nacionais (SILVA, 1969; SAVOIE, 2007; GARNICA, GOMES E ANDRADE, 2013). Como resultado, a educação na França pós-revolucionária acaba por desaguar no dualismo entre a educação popular primária e uma outra dedicada a um público muito mais reduzido e favorecido: dos que encontram condições para ascender ao longo da carreira escolar (BOURDIEU, 1998 [1966]).

Contra o que se transformou em um modelo educativo conservador,

10 Lúcia Magalhães. Síntese da evolução e da situação atual do ensino secundário no Brasil, palestra realizada na Associação Brasileira de Imprensa (ABI) para os candidatos ao concurso a Técnicos de Educação, 1939. Arquivo Gustavo Capanema, CPDOC/FGV. 
detentor de um nítido corte de classe, vieram diversas propostas para se chegar a uma escola comum, que conseguisse educar as massas evitando as habituais divisões entre a cultura literária e a cultura científica, o trabalho intelectual e o trabalho manual. ${ }^{11}$ Havia nessas propostas um determinado consenso de que a escola seria o motor das democracias, ainda mais se procurasse inverter os papéis tradicionais de professores e estudantes no processo de aprendizado, admitindo uma maior autonomia aos discentes. Anísio Teixeira trouxe essas ideias para o Brasil, importando-as dos Estados Unidos da "era progressista" (1900-1920), período em que havia um otimismo pela educação, chegando a 90\% as crianças matriculadas em escolas públicas, embora apenas $16 \%$ da população tivesse concluído o ensino médio (LUKÁCS, 2006, p. 286). Contudo, em sua visão, a escola secundária até então existente não trazia respostas para um mundo em transformação, dado que "não visava resolver nenhum problema de produção econômica, nem resolver nenhum problema material ou prático da vida corrente" (TEIXEIRA, 2005 [1956], p. 142).

Na quarta década do século XX, porém, a civilização liberal, amparada nos valores da ciência, racionalidade pública e melhoria gradativa da condição humana - por meio da iniciativa individual e de governos representativos -, entra em crise, em meio a maior catástrofe da história econômica mundial (HOBSBAWM, 1994). Francisco Campos, em 1935, compreendeu essa crise como portadora de um "novo ciclo de cultura", em que a irracionalidade despontava face à irrupção das massas:

Há como que uma volta à comunhão totêmica, sensível nas grandes concentrações urbanas do mundo moderno e, nestas, o fenômeno, apenas em começo, da tendência à superconcentração não somente sob a forma de habitações coletivas, como sob todas as demais formas de vida em comum, em que tudo se torna típico, uniforme e coletivo, ou em que todos participam de tudo, porque há uma participação recíproca ou cada um está em relação aos outros em um estado mais ou menos

\footnotetext{
${ }^{11}$ Somente com as reformas da década de 1960 os franceses caminharam mais efetivamente neste sentido, ao atingirem a sistematização do ensino, o que permitiu a introdução das "escolas compreensivas" (PROST, 2004).
} 
equívoco de participação ou de comunhão. As formas da vida íntima e pessoal tendem a desaparecer. $\mathrm{O}$ estado de massa gera a mentalidade de massa, propaga e intensifica as expressões próprias a essa mentalidade. A moderna teologia política é o resultado de uma cultura de massas, pois que, em cada época os processos espirituais de integração política só podem ser determinados pelas formas expressivas ou dominantes da sua cultura (CAMPOS, 2001, p. 21).

Os homens que fizeram a "revolução de 1930" encontraram um Brasil ainda predominante rural, onde a política era expressão do velho mando oligárquico. Em pouco tempo, porém, teria início um intenso processo de modernização, capaz de provocar o deslocamento de grandes contingentes humanos para os maiores centros urbanos e suas periferias. A contar do primeiro censo realizado entre nós, em 1871, o percentual de habitantes nas regiões urbanas evoluiu de 5,9\% para 31,24\% em 1940, ou seja, uma explosão de cinco vezes mais. Metade desse aumento se sucedeu após a década de 1920, quando a população das cidades passou de 3.287.448 para 12.880.182 de habitantes (OLIVEN, 2010, p. 67).

Essa mudança seria puxada ainda mais pelos números da indústria, que mostraram um crescimento acima do Produto Interno Bruto (PIB) no período entre 1933 e 1945, conforme o quadro abaixo:

Quadro I - Crescimento da produção industrial brasileira versus crescimento do Produto Interno Bruto (1933-1945).

\begin{tabular}{|c|c|c|}
\hline & $\begin{array}{c}\text { PRODUÇÃO } \\
\text { INDUSTRIAL } \\
\text { (CRESCIMENTO) }\end{array}$ & $\begin{array}{c}\text { PRODUTO INTERNO } \\
\text { BRUTO } \\
\text { (CRESCIMENTO) }\end{array}$ \\
\hline $1933^{-1936}$ & $14,1 \%$ & $7,4 \%$ \\
\hline $1937-1941$ & $8,3 \%$ & $4,5 \%$ \\
\hline $1942-1945$ & $4,3 \%$ & $1,8 \%$ \\
\hline
\end{tabular}

Fonte: Leopoldi, 2005.

Em consequência do que Maria Antonieta Leopoldi (2005) considerou 
como o "primeiro milagre econômico brasileiro", partindo de um ponto crítico de estagnação (pois o crescimento da produção industrial no quadriênio 1929-1932 se igualou a zero), a participação industrial no PIB iria atingir níveis consideráveis até a década de 1940. Começa a se caracterizar assim uma tendência, depois confirmada, de concretização do desenvolvimento econômico nacional nos quadros da formação de um capitalismo industrial alinhado a uma presença mais evidente do Estado e à entrada do capital estrangeiro.

No limiar deste cenário, os dirigentes da administração pública federal iniciaram a estruturação do ensino secundário. Optaram por fazê-lo um ramo do ensino médio reservado aos que tivessem condições de passar por um longo período de estudos teóricos, após o qual estariam aptos a exercerem o papel de condutores morais e intelectuais da nação. $\mathrm{O}$ modelo finalmente estabelecido afastava-se do que era preconizado por liberais como Anísio Teixeira, reproduzindo muito dos padrões escolares franceses acima mencionados, embora não escapasse à influência da reforma escolar empreendida na Itália fascista.

\section{MODERNIZAÇÃO DO ENSINO SECUNDÁRIO}

Deveu-se à reforma de Francisco Campos (viabilizada pelos decretos-lei 19.890, de 18 de abril de 1931; 20.946, de 7 de outubro de 1931 e 21.241, de 4 de abril de 1932) o início da modernização do ensino secundário no Brasil. Em decorrência desse conjunto de atos normativos, aprovados em um período de recesso da representação política, foram criadas as condições para a futura nacionalização da sua cultura escolar. ${ }^{12}$

\footnotetext{
${ }^{12}$ Dallabrida (2009) trata de uma modernização nacionalizada do ensino secundário a partir da reforma Francisco Campos. Aproveitamos este conceito, com a ressalva de que apesar de todo o esforço normativo ocorrido após a "revolução de 1930", esta modernização teria muita dificuldade em ecoar sobre todo o território nacional. O Estado Novo tornou isso mais factível, em meio a expedientes autoritários e o acordo entre a administração federal e os setores mais conservadores da sociedade, tornando possível a cristalização de um modelo pedagógico elitista para o ensino médio, em que o secundário seguia destacado dos demais ramos.
} 
O efeito número um dessa mudança legislativa seria o de bloquear a educação secundária fora das unidades escolares. Na Primeira República, o ir e vir das muitas reformas educacionais fez com que surgissem brechas a respeito da frequência escolar obrigatória para os secundaristas. A ambiguidade da lei permitia a continuidade do ensino secundário voltado apenas ao preparatório dos exames de admissão no ensino superior, herdado do Império; mesmo quando se pretendia atingir a seriação, como no caso das reformas Epitácio Pessoa - 1901 e Rocha Vaz - 1925 (BOMENY, 2015). Para introduzir definitivamente o sistema seriado, a reforma Campos deixou expresso em seu artigo 33:

Será obrigatório a frequência das aulas, não podendo prestar exame, no fim do ano, o aluno cuja frequência não atingir a três quartos da totalidade das aulas da respectiva série. ${ }^{13}$

Sustentando a seriação do ensino na obrigatoriedade e controle da presença escolar, o decreto publicado em abril de 1931 abria a perspectiva de ter o ramo secundário do nível médio como um espaço mais amplo na formação dos indivíduos em transição para a vida adulta. $\mathrm{O}$ relatório ministerial apresentado ao "Senhor chefe do governo provisório" deixava isso claro, ao dizer que:

De todos os ramos de nosso sistema de educação, é exatamente o ensino secundário o de maior importância, não apenas do ponto de vista quantitativo, como do qualitativo, destinando-se ao maior número e exercendo, durante a fase mais propícia do crescimento físico e mental, a sua influência na formação das qualidades fundamentais da inteligência, do julgamento e do caráter. A finalidade do ensino secundário é, de fato, muito mais ampla do que a que se costuma atribuir-lhe. Via de regra, o ensino secundário tem sido considerado entre nós um simples instrumento de preparação dos candidatos ao ensino superior, desprezando-se assim, a sua função eminentemente educativa, que consiste precisamente, no desenvolvimento das faculdades de apreciação, de juízo e de critério, essenciais a todos os ramos da atividade humana, e, particularmente, no treino da

${ }_{13}$ BRASIL. Decreto No 19.890, de 18 de abril de 1931. 
Encontrar a função educativa do ensino secundário era uma demanda recorrente entre os críticos da sua forma acentuadamente propedêutica. No senso mais estrito, essa função teria o seu perfil demonstrado na composição do currículo. A historiografia da educação indica que o currículo da reforma Francisco Campos trazia uma "distribuição mais equilibrada entre estudos literários e científicos no curso fundamental e a revitalização do cientificismo" (SOUZA, 2008, p. 153), ou então, um currículo enciclopédico, que procurava abranger vastos domínios do conhecimento (NUNES, 1962; SILVA, 1969; DALLABRIDA, 2009). De um modo ou de outro, isso aponta para a contradição que maculou o início da expansão do ensino secundário no Brasil, precisamente colocada por Gildásio Amado (1973, p. 3): "Evoluindo para se tornar um ensino de massa, a organização legal se mantinha dentro das linhas antigas, com objetivos e características quase exclusivos de educação destinada a uma minoria".

Assinada pelo ministro Gustavo Capanema em 1942, a Lei Orgânica do Ensino Secundário manteve o sentido elitista desse ramo do ensino médio, tolhendo, porém, os aspectos de modernidade pedagógica encontrados na política anterior. Estes se manifestaram sobretudo na exposição de motivos do decreto 19.890. Encontramos nesse documento uma proposta de educação voltada para a resolução de problemas, aberta aos métodos ativos de aprendizado e interessada em preparar os educandos para uma "época de transformações e de mudança" (CAMPOS, 1941, p. 49).

Apesar desta intenção inicial, coerente com os princípios pedagógicos da Escola Nova, seletivamente esposados por Francisco Campos desde a sua passagem pela secretaria de Justiça de Minas Gerais, na gestão do governador Antônio Carlos Ribeiro de Andrada, ainda antes da "revolução de 1930", não 
houve maior irradiação dos seus princípios no sistema escolar. ${ }^{14}$ Prevaleceu, sobretudo após a instalação do Estado Novo, uma política educacional conservadora, orientada pelos desejos de um nacionalismo autoritário e apoiada nos cânones do catolicismo e do militarismo, mesmo que em muitos aspectos ainda permanecesse a forma moderna de administrar a educação enquanto política pública.

A dinâmica do Ministério da Educação demonstra que o nacionalestatismo da Era Vargas representou uma experiência de modernização conservadora. ${ }^{15}$ No decorrer desse processo, a longa reforma do ensino secundário, enquadrada na memória oficial como a junção dos vetores de expansão e qualificação deste tipo de oferta escolar, receberia de Capanema os ajustes mais definitivos.

O primeiro vetor da reforma se manifestou no crescimento contínuo do número de matrículas, embora estas não estivessem sendo absorvidas pela ampliação da rede pública. Para atingir este objetivo, a "revolução de 1930" expandiu ainda mais a estratégia da equiparação, em uso desde a Primeira República. O Estado novamente era afastado do investimento na abertura de escolas, centrando o seu papel na regulamentação e fiscalização da atividade privada (SILVA, 1969; ROMANELLI, 1980; ROCHA, 2000; DALLABRIDA, 2009). Em um exemplo de continuidade administrativa, o Departamento

\footnotetext{
${ }^{14}$ Um estudo sobre a adaptação do Atheneu Sergipense às inovações trazidas pela reforma de Francisco Campos mostra a demora pela qual os estatutos deste colégio de ensino secundário foram modificados para atender as novas exigências legais. Isso revela a dificuldade em nacionalizar o ensino secundário em um estado distante da capital federal, haja vista que as adaptações necessárias só ocorreriam após a portaria ministerial datada de 17 de março de 1936, ou seja, durante a administração de Gustavo Capanema (SOUZA, 2011).

${ }_{15}$ Toco nesse ponto a partir de uma tradição intelectual, consagrada por Barrington Moore Jr em As origens sociais da ditadura e da democracia: senhores e camponeses nas origens do mundo moderno, que recebeu uma forte acolhida no Brasil. A modernização conservadora enquanto via de acesso à modernidade situada fora da vertente clássica das revoluções burguesas, sublinha as contradições encontradas no pacto entre um Estado modernizador e os grandes proprietários rurais. O Brasil de Vargas protagonizou um caso célebre de aumento do ritmo da industrialização e crescimento urbano desacompanhado de mudanças significativas na estrutura da propriedade rural. Passa a haver um compromisso em que o mando oligárquico tradicional permanece influente. Para uma síntese desse processo, inclusive do que o autor considera o seu esgotamento, ver Domingues (2002).
} 
Nacional de Ensino (DNE), dirigido desde 1927 pelo professor Aloysio de Castro, ainda na estrutura administrativa do Ministério da Justiça, adquire enorme protagonismo, sendo o órgão responsável pelo serviço de inspeção dos estabelecimentos oficialmente equiparados. ${ }^{16}$

Inicialmente, a nova organização do ensino secundário atribuiu aos inspetores poderes relativos ao controle das práticas didático-pedagógicas e das avaliações dos professores. ${ }^{17}$ No final de 1931, a inspeção seria detalhada e ampliada para colocar regras mais abrangentes sobre a totalidade da instituição escolar. ${ }^{18}$ Desenvolveu-se assim um desenho de política pública que levaria ao "empresariamento cartorial" da educação (ROCHA, 2000). Neste sentido, embora o Estado pouco se ocupasse do investimento em infraestrutura e contratação de professores, caber-lhe-ia centralizar as decisões sobre a organização escolar, repetindo no setor educacional o movimento que caracterizou o primeiro governo Vargas, com a criação de interventorias, conselhos e comissões técnicas capazes redistribuir o poder decisório a favor da administração federal.

16 BRASIL. Decreto-lei $\mathrm{n}^{0}$ 19.890, de 18 de abril de 1931. Art. $\mathrm{n}^{0}$ 51. "Subordinado ao Departamento Nacional do Ensino, é criado o serviço da inspeção aos estabelecimentos de ensino secundário, sendo seus órgãos, junto àqueles, os inspectores e os inspetores gerais". O DNE foi criado originalmente em 1925, dentro da estrutura administrativa do Ministério da Justiça e Negócios Interiores, servindo como embrião do futuro Ministério da Educação (CAMARGO, 2015).

${ }^{17}$ Idem. Art. 56: Incumbe ao inspetor inteirar-se, por meio de visitas frequentes, da marcha dos trabalhos de sua seção, devendo para isso, por série e disciplina: a) assistir a lições de exposições e demonstração pelo menos uma vez no mês; b) assistir igualmente, pelo menos uma vez por mês, a aulas de exercícios escolares ou de trabalhos práticos dos alunos, cabendo-lhes designar quais destes devam ser arguidos e apreciar o critério de atribuição das notas; c) acompanhar a realização das provas parciais que só poderão ser efetuadas sob sua imediata fiscalização, cabendo-lhe ainda aprovar ou modificar as questões a serem propostas; d) assistir às provas finais, sendo-lhe facultado arguir e atribuir nota ao examinado.

18 BRASIL. Decreto-lei $\mathrm{n}^{0}$ 20.496, de 7 de outubro de 1931. Para obter a permissão de expedir diplomas nacionalmente válidos, as entidades particulares teriam que "dispor de edifício, instalações e material didático que preencham os requisitos mínimos organizados pelo Departamento Nacional de Ensino e aprovados pelo ministro da Educação e Saúde Pública" (Art. $3^{\circ}$ ). Além de comprovar: a) eficiência do ensino; b) aptidão do professorado para o aperfeiçoamento dos métodos de aprendizagem; c) remuneração adequada dos professores; d) subsistência de condições higiênicas, pedagógicas e morais; e) adoção de métodos de disciplina escolar e de atividades sociais extraclasse, condicentes com o desenvolvimento progressivo do espírito de responsabilidade por parte do aluno. (Art. $5^{\circ}$ ). O processo de equiparação dependia ainda do pagamento de uma quota no valor de 12:000 $\$ 000$ (doze contos de réis). 
O segundo vetor se manifestou na montagem do currículo escolar. Este, por sua vez, teria mais características de ruptura entre as duas reformas do período. As alterações curriculares feitas, contudo, se conectam ao sentido da expansão privatista. Isso explica porque a formação enciclopédica da reforma de 1931 receberia as mais duras críticas dos representantes das instituições particulares de ensino, na maioria escolas confessionais católicas, que se diziam defensoras das humanidades clássicas, em especial da valorização do latim como artifício da inteligência (SOUZA, 2009).

Efetuada em um contexto de grave centralização política e administrativa, a reforma Capanema procurou elevar o ensino secundário a um padrão não só condizente com as expectativas de obtenção de mão de obra qualificada para as funções intermediárias do setor privado e do aparato burocrático-estatal em construção, mas também alinhado ao teor ideológico de um regime que se imaginava capaz de gestar um homem novo para um novo Brasil. Esse homem novo era o trabalhador plenamente integrado em uma ordem social que, desde a introdução da legislação trabalhista, o teria reconhecido como detentor de direitos inalienáveis, dando por encerrada a necessidade de uma atitude conflitiva entre patrões e empregados (GOMES, 1982). Uma vez que se considerava resolvido o problema social, a aquisição do capital educacional era vista pela ideologia estadonovista como um forte elemento de ascensão individual por mérito. Nota-se, entretanto, ao se comparar as vias de acesso encontradas no ensino médio, que a distribuição desse mérito se dava de forma desigual. Nesse contexto, a reforma Capanema reforça mais uma vez o prestígio do ensino secundário, especialmente ao indicar que:

Aos alunos que concluírem quer o curso clássico quer o curso científico mediante a prestação dos exames de licença será assegurado o direito de ingresso em qualquer curso do ensino superior, ressalvadas, em cada 
caso, as exigências peculiares à matrícula. ${ }^{19}$

Com essa redação, a Lei Orgânica do Ensino Secundário manteve a dualidade entre a formação acadêmica e profissional, dificultando a equivalência dos ramos do ensino médio para efeito de ingresso no ensino superior. ${ }^{20}$ Ficou definido ainda um período maior para a fase de especialização, com o colégio cursado em três anos. Essa fase, porém, seria reduzida a duas modalidades. Assim se procurava atenuar as críticas quanto à precocidade das escolhas profissionais, advinda da divisão tripartite do ciclo complementar na reforma de 1931.

No lugar das três áreas de concentração anteriores - dentro das quais eram formadas turmas preparatórias para Humanidades e Ciências Sociais (candidatos ao curso de Direito); Ciências Biomédicas (candidatos aos cursos de Farmácia, Medicina e Odontologia) e Ciências Exatas e Espaciais (candidatos aos cursos de Arquitetura e Engenharia), optou-se pela divisão entre o científico e o clássico.

Essa e outras alterações resultaram da pressão exercida pelo setor da educação privada, capitaneado naquele momento pelas instituições católicas de ensino.

\footnotetext{
19BRASIL. Decreto-lei ${ }^{0} 4.244$ de 9 de abril de 1942.

${ }^{20}$ O debate educacional da década de 1950 questionou a primazia do ensino secundário como via de acesso à formação superior, levando à aprovação de uma legislação relativa ao regime de equivalências, em três momentos: a Lei 1.076 (1950), a Lei 1.821 (1953) e a Lei 3.104 (1957). Procurou-se assim: 1) liberalizar a transição dos estudantes originários de uma formação não ginasial para os cursos clássico e científico, mediante a prestação de exames das disciplinas faltantes; 2) permitir a participação nos exames vestibulares aos concluintes dos cursos técnicos, normal de segundo ciclo, seminário e formação para o oficialato das polícias militares. No entanto, como admite Nunes (2000, p. 53), somente "a Lei de Diretrizes e Bases, em seu artigo 79, estabeleceu a equivalência de todos os cursos de nível médio ao determinar a possibilidade de todos os concluintes do segundo ciclo prestarem vestibular para qualquer curso superior, sem necessidade de complementação".
} 


\section{ACOMODAÇÕES DO PÚBLICO AO PRIVADO}

Uma farta correspondência entre o ministro da Educação e o padre jesuíta Arlindo Vieira, dirigente do colégio Santo Inácio, preservada no arquivo particular de Gustavo Capanema, sob a guarda do Centro de Pesquisa e Documentação de História Contemporânea do Brasil da Fundação Getúlio Vargas (CPDOC/FGV), na cidade do Rio de Janeiro, exemplifica a afirmativa feita no parágrafo anterior. ${ }^{21}$ Nela se destaca uma carta dirigida ao presidente Getúlio Vargas, depois despachada para o gabinete do ministro Capanema, na qual o missivista católico faz uma síntese de dois artigos seus publicados na imprensa, nos quais criticava "os programas ridiculamente enciclopédicos, a industrialização do ensino e a especialização prematura". Além disso, ele se voltava também contra "o odioso formalismo burocrático que ata as mãos dos bons colégios e lhes tira toda a possibilidade de fazer alguma coisa em prol da nossa inteligente mocidade" 22.

Esse quadro de insatisfação não era apenas uma visão particular do jesuíta, mas representava uma parcela considerável do setor privado da educação. ${ }^{23}$ A peleja se dava contra os excessos da reforma de Francisco Campos. Mesmo que essa legislação, como vimos anteriormente, tivesse promovido um aumento do número de matrículas por meio da efetivação da estrutura seriada e da frequência escolar obrigatória de $75 \%$ das aulas, a orientação cientificista dos programas de estudo e a forma cartorialista de administrar as relações públicoprivado desagradaram os proprietários dos estabelecimentos de ensino. Nesse

\footnotetext{
${ }^{21} \mathrm{O}$ arquivo particular de Gustavo Capanema está totalmente digitalizado, sendo possível acessálo no endereço eletrônico https://docvirt.com/docreader.net/docmulti.aspx?bib=fgv_gc, onde se visualiza a descrição do acervo. A troca de mensagens entre o padre Arlindo Vieira e o ministro Gustavo Capanema pode ser acessada na série correspondentes/GC b Vieira, A.

${ }_{22}$ Carta do Padre Arlindo Vieira ao "Excmo. Sr. Dr. Getúlio Vargas". Rio de Janeiro, 23 de maio de 1940. Arquivo Gustavo Capanema, série correspondentes/CG b Vieira, A. Disponível em https://docvirt.com/docreader.net/DocReader.aspx?bib=ARQ_GC_B\&pagfis=10159 [Acesso em 06 jul. 2020].

${ }^{23}$ Em sua batalha por uma reforma da legislação referente ao ensino secundário, o padre Arlindo Vieira publicou inúmeros artigos na imprensa nacional e estrangeira, além dos livros $O$ problema do ensino secundário (1936) e O ensino das humanidades (1936).
} 
contexto, a entrada de Gustavo Capanema no Ministério da Educação seria considerada uma oportunidade para que fossem realizados os devidos ajustes.

Assim, vejamos como isso se dá no caso de uma solicitação feita pelo padre Arlindo Vieira, relativa à inclusão de provas de segunda época para os estudantes que tendo obtido média global 5,o ficassem dependendo de uma ou duas disciplinas. Na documentação consultada, o pleito aparece pela primeira vez em uma carta datada de 24 de junho de 1939, quando o religioso tratou das "medidas de emergência" a serem tomadas antes de uma reforma integral do ensino. $\mathrm{O}$ assunto retorna por mais de uma vez na referida correspondência, sendo considerado caro às famílias a aos bons colégios. Por sua importância, torna-se até mesmo objeto de uma proposta legislativa negociada com o ministro:

Prezado amigo, Dr. Gustavo Capanema,

Não o tendo encontrado aqui no Ministério, deixei em mãos do sr. Drummond o trabalhinho que V. Exc. se dignou de me dar, isto é, uma fórmula do decreto-lei relativo às medidas que tão oportuna e sabiamente vai V. Excia. revogar. Confiando na bondade de V. Excia. e no seu desejo de satisfazer a tão justo pedido das famílias e dos bons colégios, incluí o exame de segunda época para os que, tendo obtido nota global 5,o (o que não é fácil) ficaram dependendo de uma ou duas matérias. É a meu ver a medida mais urgente de quantos vem pleiteando as famílias e a imprensa do país. Concedendo tudo quanto se acha no rascunho que eu apresento a V. Excia., V. Excia. receberá incondicionais aplausos das famílias e dos bons colégios. ${ }^{24}$

O "trabalhinho" acertado com o "Prezado amigo, Dr. Gustavo Capanema" foi entregue na forma de quatro artigos legislativos datilografados, dentre os quais, o de número dois dizia expressamente: "Os alunos que obtiverem nota igual ou superior a cinquenta no conjunto das disciplinas e inferior a trinta em uma ou duas, poderão submeter-se a novo exame dessas disciplinas na primeira

${ }^{24}$ Carta do Padre Arlindo Vieira ao "Prezado amigo doutor Gustavo Capanema", s/d. Arquivo Gustavo Capanema, série correspondentes/CG b Vieira, A. Disponível em https://docvirt.com/docreader.net/DocReader.aspx?bib=ARQ_GC_B\&pagfis=10154 [Acesso em 10 jul. 2020]. 
quinzena de março". 25 Era a legalização de um pleito favorável ao setor empresarial do ensino, uma vez que diminuía os riscos das famílias decidirem por trocar os filhos de escola após uma reprovação direta.

A facilidade com que o padre Arlindo Vieira transitava nos corredores do Ministério da Educação elucida a existência de um alinhamento deste com as expectativas dos mais expressivos e elitistas colégios particulares da capital republicana. ${ }^{26}$ Para esse segmento, a prevalência da cultura humanista, além de estar inserida em uma determinada visão de mundo, era algo funcional do ponto de vista dos custos implicados na manutenção do empreendimento educativo. A correspondência encontrada no arquivo particular de Gustavo Capanema corrobora com esta afirmativa ao mostrar a disputa sobre os programas de ensino e a distribuição da quantidade de horas-aula por semana para cada disciplina. Em uma carta datada de 11 de abril de 1942, poucos dias após a publicação do decreto contendo a Lei Orgânica do Ensino Secundário, dizia o religioso:

\footnotetext{
Prezado amigo Dr. Gustavo Capanema.

Atenciosas saudações,
}

Sigo amanhã pelo noturno para São Paulo, em exercício dos meus ministérios sacerdotais e, de lá, só regressarei a 2 de junho.

Aguardo a publicação dos currículos para escrever sobre o assunto. Mostrarei como o número de aulas de ciências que neles figuram é incomparavelmente superior ao dos programas franceses e italianos.

Os colégios mostraram-se um pouco alarmados com as disciplinas subsidiárias. Como poderão os externatos dar uma aula diária de ginástica a todas as turmas?

Esperarmos que o senhor há de reduzir tudo isso ao mínimo, inclusive o desenho, os trabalhos manuais e o canto orfeônico que não deveriam

\footnotetext{
25Idem.

Disponível

em

https://docvirt.com/docreader.net/DocReader.aspx?bib=ARQ_GC_B\&pagfis=10158 [Acesso em 10 jul. 2020].

${ }^{26} \mathrm{Na}$ carta anteriormente citada, o jesuíta faz referência a um artigo de Laura Jacobina Lacombe, proprietária do Colégio Jacobina, publicado no Jornal do Brasil, no qual a educadora apoiava esse mesmo pleito.
} 
A preocupação com o elevado número de aulas semanais de ciências expunha não apenas as restrições das escolas confessionais católicas ao ensinamento de teorias que pudessem conflitar com as verdades defendidas pelo Vaticano, mas também a indisposição destas para investir em ambientes adequados à demonstração dos experimentos científicos. O alarme dos colégios particulares com o excesso das aulas de ginástica (e demais "disciplinas subsidiárias") aponta no mesmo sentido. Pode-se concluir então que a batalha pelo humanismo era uma luta por determinada cultura escolar, incluindo a presença de uma arquitetura dos espaços cognitivos e a valorização do preparo elitista ao nível superior.

Tudo isso convergia com o ambiente institucional existente: a ditadura varguista do Estado Novo e a Constituição outorgada em novembro de 1937. Esta, no artigo ${ }^{0} 128$, o primeiro do capítulo sobre educação e cultura, afirmava: "A arte, a ciência e o ensino são livres à iniciativa individual e a de associações ou pessoas coletivas públicas e particulares". Logo em seguida, no parágrafo único, era considerado "dever do Estado contribuir, direta e indiretamente" para este fim. ${ }^{28}$ No entanto, a participação direta do Estado Nacional no fomento à educação era extremamente limitada, cabendo a ele um papel indutor em conjunto com a inciativa privada. Essa associação entre o Estado e a iniciativa privada correspondia ao que o texto constitucional definiu como o "direito natural" das famílias sobre a "educação integral da prole". ${ }^{29}$

A satisfação das famílias, em geral, vinha acompanhada da moralidade

\footnotetext{
${ }_{27}$ Carta do Padre Arlindo Vieira ao "Prezado amigo, doutor Gustavo Capanema", 11 de abril de $1942 . \quad$ Disponível em https://docvirt.com/docreader.net/DocReader.aspx?bib=ARQ_GC_B\&pagfis=10168. [Acesso em 10 jul. 2020].

${ }^{28}$ BRASIL. Constituição dos Estados Unidos do Brasil, de 10 de novembro de 1937. Capítulo "Da Educação e da Cultura", artigo n ${ }^{0} 128$.

29 BRASIL. Constituição dos Estados Unidos do Brasil, de 10 de novembro de 1937. Capítulo "Da família", artigo $\mathrm{n}^{\mathrm{0}} 125$.
} 
religiosa oferecida no mercado escolar pelas instituições educacionais católicas e afins. Estas obtiveram o apoio do Estado para difundir as suas concepções acerca da formação dos secundaristas, como procedeu no fomento ao estudo do Latim. Após a redução do quantitativo de aulas semanais provocada pela reforma Francisco Campos, que intensificou o estudo das línguas modernas, o Latim retorna com força na reforma Capanema, resultando em um "boom editorial" e no "lançamento de uma quantidade sem fim de métodos e materiais didáticos" (SOBRINHO, 2013, p. 48). A correspondência entre Capanema e o padre Arlindo Vieira expõe a vontade do professorado católico em dominar esse nicho do mercado editorial, aproveitando-se do diálogo aberto no Ministério da Educação. Um movimento neste sentido encontra-se nas críticas dirigidas ao latinista do Colégio Pedro II, Ernesto Faria, autor de O Latim pelos textos. É o que está contido no trecho abaixo:

\begin{abstract}
Quanto ao programa de Latim digo confidencialmente a V. Exc. (e creio que faltaria ao meu dever se deixasse de esclarecer V. Exc. a este respeito) que vários de professores de Latim lamentaram que os programas do ginásio tenham sido elaborados em função do manual $O$ Latim pelos textos, do qual foi logo tirada nova edição e se acha largamente difundida pelos ginásios. Não sei até que pontos eles têm razão.

$\mathrm{O}$ que eu posso assegurar a V. Exc. é que esse livro, "O Latim pelos textos" desonra o nosso ensino. Está repleto de erros grosseiros. Há, entre as notas, despautérios que não se podem perdoar a alunos que tem algum conhecimento do latim. Algumas alunas da universidade descobriram esses erros, vieram ter comigo e infelizmente eu tive que dar-lhes razão. Por esse motivo pedi ao P. Magne que preparasse um texto para os quatro anos do ginásio, o que ele está fazendo. ${ }^{30}$
\end{abstract}

Sem embargo, a disputa pela legitimidade do ensino do Latim, historicamente uma especialidade dos intelectuais da Igreja Católica, demonstra

\footnotetext{
${ }^{30}$ Carta do Padre Arlindo Vieira ao "Prezado amigo, doutor Gustavo Capanema", s/d. Arquivo Gustavo Capanema, série correspondentes/CG b Vieira, A. Disponível em https://docvirt.com/docreader.net/DocReader.aspx?bib=ARQ_GC_B\&pagfis=10183 [Acesso em 10 jul. 2020].
} 
a importância dada pelos representantes dessa instituição em induzir o Estado a tomar decisões favoráveis aos seus objetivos. Neste caso, procurou-se favorecer o trabalho desenvolvido pelo padre jesuíta Augusto Magne, docente da recém fundada Pontifícia Universidade Católica do Rio de Janeiro (PUC-Rio) e autor de uma bibliografia que só teria a crescer depois da Lei Orgânica do Ensino Secundário. ${ }^{31}$

No decurso da correspondência trocada entre o padre Arlindo Vieira e o ministro Capanema, chama atenção ainda um pedido feito pelo jesuíta para a oficialização do Seminarium Latinitatis Classicae, em São Paulo. Esta solicitação entrava em contradição com a política universitária da "revolução de 1930", favorável à abertura das faculdades de filosofia, ciências e letras como forma de incentivar a formação docente para o ensino secundário:

\begin{abstract}
O Padre Magne está tratando de preparar bons manuais de grego e de latim. Creio que Vossa Excelência poderá ajudá-lo muito para o bom êxito desse trabalho. Peço encarecidamente a Vossa Excelência que não se esqueça do Seminarium Latinitatis Classicae de S. Paulo. Esse Seminarium poderá ser um viveiro de excelentes professores de latim. V. Exc. Poderá até oficializá-lo e conceder registro de professor de latim aos que fizerem aí o curso durante três anos. $3^{2}$
\end{abstract}

Assim, em meio a uma conjuntura política que apontava para a presença de uma experiência autocrática, a relação de cortesia e proximidade em que conviveram o ministro e o religioso sugere uma situação pouco republicana, envolvendo favorecimentos mútuos, no plano material e simbólico. O resultado mais efetivo dessa relação seria o endosso da cultura escolar elitista,

\footnotetext{
${ }^{31}$ No decorrer da década de 1940, o padre Magne lançou os seguintes livros: Primeira gramática latina (1943), Antologia latina para primeira série ginasial (1944), Antologia latina para a segunda série ginasial (1944), Antologia latina para a terceira série ginasial (1944), Antologia latina da quarta série ginasial (1944) e Curso colegial de Latim (1946).

32 Carta do Padre Arlindo Vieira ao "Prezado amigo, doutor Gustavo Capanema", 11 de abril de 1942. Disponível em https://docvirt.com/docreader.net/DocReader.aspx?bib=ARQ_GC_B\&pagfis=10168. [Acesso em 10 jul. 2020].
} 
nacionalizada em meio aos expedientes autoritários do Estado Novo, que adquire feições monumentais e um grande poder de resistência às mudanças advindas da queda do primeiro varguismo.

\section{CONSIDERAÇÕES FINAIS}

Para as gerações de brasileiros e brasileiras que viveram a adolescência e o início da vida adulta nas décadas de 1940 e 1950, ainda se mantém a lembrança de um tempo em que a escola secundária era valorizada pelo rigor no processo de aprendizado e pelos ritos disciplinares para se atingir esse padrão. Obviamente, essa lembrança é socialmente demarcada. Isso porque, as opções em torno da modernização conservadora levaram a um modelo educacional privatista, excludente, produtor de reprovação e abandono escolar em larga escala. Considerando o ano estatístico de 1958, chegamos a um resultado favorável a essa conclusão:

Quadro II - Estudantes secundaristas em número de matrículas e conclusões de curso (1958).

\begin{tabular}{|c|c|c|c|}
\hline & $\begin{array}{c}\text { MATRÍCULAS/ } \\
\text { GINASIAL }\end{array}$ & $\begin{array}{c}\text { MATRÍCULAS/ } \\
\text { COLEGIAL }\end{array}$ & CONCLUINTES \\
\hline $\begin{array}{c}\text { Rede } \\
\text { Pública }\end{array}$ & 213.821 & 36.684 & 6.479 \\
\hline $\begin{array}{c}\text { Rede } \\
\text { Particular }\end{array}$ & 392.580 & 52.078 & 12.585 \\
\hline
\end{tabular}

Fonte: IBGE - Anuário Estatístico do Brasil, 1960.

Esses números, datados de dezesseis anos após a Lei Orgânica do Estado Novo, reforçam a hipótese que se procurou demonstrar no decorrer deste artigo: a opção do Estado modernizador em fazer do ensino secundário o ramo mais atrativo do ensino médio permitiu, em meio a um processo de relativa aceleração na abertura das oportunidades escolares, a permanência de um modelo 
educacional carregadamente elitista.

Para entendermos a montagem desse quadro, não poderíamos deixar de fora as alianças construídas entre o Ministério da Educação e os representantes das escolas particulares durante a gestão de Gustavo Capanema. Foi com esse objetivo que consultamos a troca de correspondência do ministro com o padre Arlindo Vieira, a fim de apreender, na dinâmica desta relação interpessoal, o significado de um diálogo sobre a forma mais adequada de uma política pública que organizasse o ensino secundário em um tempo de ascensão mundial das massas.

Por meio dessa documentação, concluímos que entre os favores solicitados pelo representante do colégio Santo Inácio ao poder público estava em jogo a defesa de uma determinada concepção de cultura escolar, pela qual se justificava a destacada presença das instituições católicas nesse mercado. Contudo, o ajuste colocado pela reforma Capanema não contribuiu apenas para alinhar as decisões ministeriais às expectativas dos agentes privados da educação. Contribuiu também para consolidar a relação do Estado Novo com os setores mais conservadores e elitizados da sociedade, responsáveis pela matrícula e manutenção dos estudantes secundaristas.

Era mantida assim uma longa tradição brasileira de disponibilização da oferta de educação privada às "boas famílias", tendo aumentado, porém, a regulação estatal sobre a equiparação expandida dos diplomas emitidos pelas instituições particulares. Isso levou, em grande medida, o tempo de Capanema a coincidir com o "empresariamento cartorial" da educação.

As duas décadas imediatamente após a ditadura varguista continuaram registrando um difícil acesso à escolarização pós-primária (analfabetismo de $39,7 \%$ da população nacional em 1960), apresentando também um reduzido número de estudantes secundaristas diplomados pela rede pública (34\% do total, em 1958). No entanto, devido a todo um esforço de construção simbólica da memória, o imaginário social ainda abraça o legado de Capanema como responsável pelos anos dourados da educação. 


\section{REFERÊNCIAS}

AMADO, Gildásio. Educação média e fundamental. Rio de Janeiro: Livraria José Olympio Editora/Brasília, Instituto Nacional do Livro, 1973.

ARQUIVO GUSTAVO CAPANEMA. Série correspondentes. GC/ b Vieira, A. Disponível em https://docvirt.com/docreader.net/docmulti.aspx?bib=fgv_gc. Acesso em o6 jul. 2020.

BOMENY, Helena. Guardiães da razão: modernistas mineiros. Rio de Janeiro: Ed. UFRJ/Tempo Brasileiro, 1994.

BOMENY, Helena. Reformas educacionais. In: ABREU, Alzira. Alves de; CARNEIRO, José Alan Dias (Org.). Dicionário Histórico-Biográfico Brasileiro da Primeira República (1889-1930). Rio de Janeiro: Ed. FGV, 2015. Disponível em http://cpdoc.fgv.br/sites/default/files/verbetes/primeirarepublica/REFORMAS\%20EDUCACIONAIS\%20.pdf. Acesso em o8 mai. 2020.

BOURDIEU, Pierre. A escola conservadora: desigualdades frente à escola e à cultura. In: NOGUEIRA, Maria Alice.; CATANI, Afrânio (Org.). Escritos de educação. Petrópolis, Vozes, 1998 [1966], pp. 39-64.

BRASIL. Presidência da República. Constituição da República dos Estados Unidos do Brasil, de 10 de novembro de 1937. Disponível em http://www.planalto.gov.br/ccivil_03/Constituicao/Constituicao37.htm.

Acesso em 02ago. 2020.

BRASIL. Presidência da República. Decreto-lei $N^{o}$ 19.89o, de 18 de abril de 1931. Disponível em https://www2.camara.leg.br/legin/fed/decret/19301939/decreto-19890-18-abril-1931-504631-publicacaooriginal-141245-pe.html. Acesso em 28 ago. 2019.

BRASIL. Presidência da República. Decreto-lei $N^{o}$ 20.496, de 7 de outubro de 1931. Disponível em https://www2.camara.leg.br/legin/fed/decret/19301939/decreto-20496-7-outubro-1931-504129-publicacaooriginal-1-pe.html. Acesso em 03 abr. 2020.

BRASIL. Presidência da República. Decreto-lei $N^{o}$ 21.241, de 4 de abril de 1932. Disponível em https://www2.camara.leg.br/legin/fed/decret/19301939/decreto-21241-4-abril-1932-503517-publicacaooriginal-81464-pe.html. Acesso em 03 abr. 2020.

BRASIL. Presidência da República. Decreto-lei $N^{o}$ 4.244, de 9 de abril de 1942. Disponível 
http://www.histedbr.fe.unicamp.br/navegando/fontes_escritas/5_Gov_Vargas /decreto-lei\%204.244-1942\%20reforma\%20capanemaensino\%20secund\%E1rio.htm. Acesso em 30 jun. 2019.

BRASIL. Presidência da República. Exposição de motivos do Decreto-lei $N^{o}$ 4.244, de 9 abril de 1942. Disponível em https://www2.camara.leg.br/legin/fed/declei/1940-1949/decreto-lei-4244-9abril-1942-414155-133712-pe.html Acesso 30 jun. 2020.

CAMARGO, Angélica Ricci. Ministério da Justiça e Negócios Interiores: um percurso republicano (1891-1934). Rio de Janeiro: Arquivo Nacional, 2015. Disponível em: http://arquivonacional.gov.br/images/virtuemart/product/Ministerio_justica_ negocios_interiores.pdf. Acesso em 06 jul. 2020.

CAMPOS, Francisco. Educação e cultura. Rio de Janeiro: Livraria José Olímpio Editora, 1941.

CAMPOS, Francisco. O Estado Nacional. Brasília: Senado Federal, 2001.

Cultura Política (Revista Mensal de Estudos Brasileiros), n. 21 (Edição comemorativa do $5^{\mathrm{o}}$ aniversário do Estado Nacional). Rio de Janeiro, Departamento de Imprensa e Propaganda (DIP), novembro de 1942. Disponível em http://memoria.bn.br/pdf/163538/per163538_1942_ooo21.pdf Acesso em 16/04/2020.

DALLABRIDA, Norberto. A reforma Francisco Campos e a modernização nacionalizada do ensino secundário. Educação, Porto Alegre, v. 32, n. 2, p. 185191, mai./ago. 2009. Disponível em http://revistaseletronicas.pucrs.br/ojs/index.php/faced/article/viewFile/5520/ 4015 Acesso em 05 mai. 2020.

DOMINGUES, José Maurício. A dialética da modernização conservadora e a nova história do Brasil. DADOS - Revista de Ciências Sociais, Rio de Janeiro, Vol. 45, $\mathrm{n}^{\mathrm{0}} 3, \quad 2002, \quad$ pp. $459 \quad$ a $482 . \quad$ Disponível em https://www.scielo.br/scielo.php?script=sci_arttext\&pid=Soo1152582002000300005 Acesso em 22 jun. 2020.

GARNICA, Antônio Vicente Marafioti; GOMES, Maria Laura Magalhães; ANDRADE, Miriam Maria. A instrução pública na França revolucionária: considerações a partir do Essais surl'enseignement en general et sur celuides mathématique sem particulier, de Sylvestre-François Lacroix. História da Educação (Online), Porto Alegre, v. 17, n. 39, jan./abr., 2013, p. 129-151. Disponível 
https://repositorio.unesp.br/bitstream/handle/11449/8572/S223634592013000100008.pdf?sequence=1\&isAllowed=y Acesso em 20 mai. 2020.

GOMES, Ângela de Castro. A construção do homem novo: o trabalhador brasileiro. In: OLIVEIRA, Lúcia Lippi.; VELOSO, Mônica Pimenta; GOMES, Ângela de Castro. Estado Novo: Ideologia e poder. Rio de Janeiro: Zahar, 1982, pp. 151-166.

HOBSBAWM, Eric. A era dos extremos. O breve século XX (1914-1991), $2^{\text {a }}$ edição. São Paulo: Cia. das Letras, 1994.

HORTA, José Silvério Baía. O hino, o sermão e a ordem do dia: regime autoritário e a educação no Brasil. Rio de Janeiro: Ed. UFRJ, 1994.

IBGE. Anuário Estatístico do Brasil. Rio de Janeiro: Conselho Nacional de Estatística/Instituto Brasileiro de Geografia e Estatística, 1960. Disponível em https://biblioteca.ibge.gov.br/visualizacao/periodicos/20/aeb_1960.pdf Acesso em 30 set. 2020.

LEOPOLDI, Maria Antonieta. A economia política do primeiro governo Vargas: política econômica em tempos de turbulência. In: FERREIRA, Jorge; DELGADO, Lucília de Almeida Neves. O Brasil Republicano, vol. 2. O tempo do nacionalestatismo (do início da década de 1930 ao apogeu do Estado Novo). Rio de Janeiro: Civilização Brasileira, 2005, pp. 241-286.

LUKÁCS, John. Uma nova república: história dos Estados Unidos no século XX. Rio de Janeiro: Jorge Zahar Editor, 2006.

MANNHEIM, Karl. Sociologia da cultura. São Paulo: Perspectivas, 1974 [1933].

NUNES, Clarice. O "velho" e "bom" ensino secundário: momentos decisivos. Revista Brasileira de Educação[online], $\mathrm{n}^{0}$ 14, pp. 35-60, 2000. Disponível em https://www.scielo.br/pdf/rbedu/n14/n14a04.pdf Acesso em 12 abr. 2020.

NUNES, Maria Thetis. Ensino secundário e sociedade brasileira. Rio de Janeiro: Instituto Superior de Estudos Brasileiros, 1962.

OLIVEN, Ruben George. Urbanização e mudança social no Brasil (Online). Rio de Janeiro: Centro Eldenstein de Pesquisas Sociais, 2010. Disponível emhttps://static.scielo.org/scielobooks/z439n/pdf/oliven-9788579820014.pdf Acesso em 03 mai. 2020.

POLLAK, Michael. Memória, esquecimento, silêncio. Estudos Históricos, Rio de Janeiro, v. 2, n. 3, pp. 3-15, 1989. 
PROST, Antoine. Razões e efeitos da sistematização do ensino. Reflexões sobre o modelo de ensino francês. Pro-posições, v. 15, n. 2 (44), mai./jun., 2004. Disponível em https://www.fe.unicamp.br/pf-fe/publicacao/2250/44-dossieprosta.pdf Acesso em 16 mai. 2020.

REIS FILHO, Daniel Aarão. O nacional-estatismo brasileiro: cultura política e história. In: FERRERAS, Norberto. (Org.) A questão nacional e as tradições nacional-estatistas no Brasil, América Latina e África. Rio Janeiro: Ed. FGV/Faperj, 2015, pp. 13-39.

ROCHA, Marlos. A educação conformada. A política pública de educação no Brasil (1930-1945). Juiz de Fora: Ed. Universidade Federal de Juiz de Fora, 2000.

ROMANELLI, Otaíza. História da Educação no Brasil (1930-1973). Petrópolis, Vozes, 1980.

SAVOIE, Philippe. Criação e reinvenção dos liceus (1802-1902). História da Educação, ASPHE/FaE/UFPel, Pelotas, n. 22, p. 9-30, Mai./Ago. 2007. Disponível em https://seer.ufrgs.br/asphe/article/view/29285 Acesso em 27 mai. 2020.

SCHWARTZMAN, Simon; BOMENY, Helena.; COSTA, Wanda. Tempos de Capanema. São Paulo: Ed. Universidade de São Paulo/Rio de Janeiro: Paz e Terra, 1984.

SILVA, Geraldo Bastos. A educação secundária: perspectiva histórica e teoria. São Paulo: Nacional, 1969.

SOBRINHO, José Amarante Santos. O Latim no Brasil da primeira metade do século XX: entre leis, discursos e disputas, uma disciplina em permanência. Phaos-Revista de Estudos Clássicos, 2013 (13), pp. 39-63. Disponível em http://revistas.iel.unicamp.br/index.php/phaos/article/view/4597 Acesso em 02 ago. 2020.

SOUZA, Rosa Fátima. História da organização do trabalho escolar e do currículo no século $X X$ (ensino primário e secundário no Brasil). São Paulo: Cortez, 2008.

SOUZA, Rosa. Fátima. A renovação do currículo do ensino secundário no Brasil: as últimas batalhas do humanismo (1920-1960). Currículo sem fronteiras, v. 9, n. $\quad 1, \quad$ pp. 72-90, jan./jun. 2009. Disponível em http://www.curriculosemfronteiras.org/volgiss1articles/4-souza.pdf Acesso em 30 jun. 2020. 
SOUZA, Suely Cristina Silva. O Atheneu Sergipense nos tempos da reforma Francisco Campos. Revista Tempos e Espaços em Educação. Vol 4, n. 7, jul./dez 2011. Disponível em https://seer.ufs.br/index.php/revtee/article/view/2260 Acesso em 20 mai. 2020.

TEIXEIRA, Anísio. A escola secundária em transformação. In: TEIXEIRA, Anísio. A educação e a crise nacional. Rio de Janeiro; Ed. UFRJ, 2005 [1956], pp. 141-162.

SÉRGIO DE SOUSA MONTALVÃO é doutor em História, Política e Bens Culturais - Centro de Pesquisa e Documentação de História Contemporânea do Brasil da Fundação Getúlio Vargas (CPDOC/FGV). Professor Associado I da Universidade Federal Fluminense - UFF, no Departamento de Administração. Linhas de Pesquisa: História Política da Educação; Intelectuais e Espaço Público; Tempo Histórico e Pensamento Social; Trabalho, Memória e Organizações. Pesquisa atual: $O$ ensino secundário como política pública da modernização conservadora: a gestão Capanema (1934-1945). Coordenador do Laboratório de História, Intelectuais e Administração (LABHIA).

E-mail: sergiomontalvao@id.uff.br

(b) http://orcid.org/0000-0003-0910-0633

Recebido em: 13 de outubro de 2020

Aprovado em: 04 de abril de 2021

Editora responsável: Dóris Almeida

Associação Sul-Rio-Grandense de Pesquisadores em História da Educação - Asphe

Artigo de acesso aberto distribuído nos termos de licença Creative Commons. 